\title{
Monitoramento de micro-organismos indicadores de higiene em linha de abate de bovinos de um matadouro-frigorífico habilitado à exportação no oeste do Paraná
}

\author{
Monitoring of hygiene indicator microorganisms in a line of cattle \\ slaughter in a slaughter plant enabled for export in western Paraná
}

\author{
Juliana Luisa Brandão ${ }^{1 *}$; Erica Cristina Bueno do Prado Guirro ${ }^{2}$; \\ Paulo Sérgio de Arruda Pinto ${ }^{3}$; Luis Augusto Nero"; \\ José Paes de Almeida Nogueira Pinto ${ }^{5}$; Luciano dos Santos Bersot ${ }^{6}$
}

\begin{abstract}
Resumo
Os micro-organismos indicadores podem ser utilizados como método de avaliação da qualidade higiênicosanitária de produtos alimentícios, indicando a adequação de condições de obtenção, processamento e armazenamento dos alimentos. O presente estudo buscou avaliar a contaminação superficial de carcaças bovinas advindas de um matadouro-frigorífico sob Inspeção Federal no oeste do Paraná pela contagem de mesófilos aeróbios (AM), enterobactérias (EB), coliformes a $35^{\circ} \mathrm{C}(\mathrm{CT})$ e E. coli (EC). Foram avaliadas amostras de superfície de 25 carcaças em quatro pontos distintos e em quatro etapas do abate, por método não destrutivo. As amostras foram submetidas a diluições decimais seriadas e incubadas em placas de Petrifilm ${ }^{\mathrm{TM}}$ conforme recomendações do fabricante. Foram observadas médias de 1,46; 0,3; 0,23 e $0,21 \log \mathrm{UFC} / \mathrm{cm}^{2}$ para AM, EB, CT e EC, respectivamente. Os valores encontrados situaram-se em conformidade com os preconizados pela decisão 471/2001 da União Europeia e de vários outros autores pesquisados, indicando a eficiência higiênica no processo da indústria.
\end{abstract}

Palavras-chave: Micro-organismos, indicadores, processamento, contaminação

\begin{abstract}
Indicators microorganisms can be used as a method for evaluating the sanitary quality of food products, indicating the suitability of conditions for obtaining, processing and storage of food. This study sought to evaluate surface contamination of cattle carcasses that come from a slaughter plant under Federal Inspection in western Paraná by mesophilic bacteria (AM), Enterobacteriaceae (EB), coliform at $35^{\circ} \mathrm{C}$ (TC) and E. coli (EC). Surface samples were collected from 25 carcasses, each at 4 different points of slaughter, for non-destructive method. The samples were diluted in decimal scale and incubated in Petrifilm ${ }^{\circledR}$ plates. Were found averages of $1.46 ; 0.3 ; 0.23$ and $0.21 \log \mathrm{CFU} / \mathrm{cm}^{2}$ for AM, EB, CT and EC, respectively. The values to be found were well below those recommended by the decision $471 / 2001$ of the European Union and several other authors surveyed, indicating the effectiveness of the hygienic process industry.
\end{abstract}

Key words: Microorganisms, indicators, processing, contamination

\footnotetext{
${ }^{1}$ Pesquisadora, Universidade Federal do Paraná, UFFR, Programa de Pós Graduação em Ciência e Tecnologia de Alimentos, Palotina, PR. E-mail: j1_brandao@yahoo.com.br

${ }^{2}$ Prof ${ }^{a}$. Adjunto II, Curso de Medicina Veterinária, UFPR, Palotina, PR. E-mail: ericaguirro@ufpr.br

${ }^{3}$ Prof. Associado II, Dept ${ }^{\circ}$ de Veterinária, Universidade Federal de Viçosa, UFV, Viçosa, MG. E-mail: pintopsa@ufv.br

${ }^{4}$ Prof. Adjunto III, Dept ${ }^{\circ}$ de Veterinária, UFV, Viçosa, MG. E-mail: nero@ufv.br

${ }^{5}$ Prof. Assistente Dr., Dept ${ }^{\circ}$. de Higiene Veterinária e Saúde Pública, Universidade Estadual Paulista Júlio de Mesquita Filho, UNESP, Botucatu, SP. E-mail: josepaes@fmvz.unesp.br

${ }^{6}$ Prof. Adjunto IV, Curso de Medicina Veterinária, UFPR, Palotina, PR. E-mail: lucianobersot@ufpr.br

* Autor para correspondência
} 


\section{Introdução}

A qualidade e a inocuidade de produtos cárneos podem ser estimadas através da pesquisa de diversos indicadores, como os aeróbios mesófilos e coliformes. A enumeração de aeróbios mesófilos fornece uma estimativa da população geral de micro-organismos que estão presentes nos produtos cárneos, e altos níveis de contaminação estão associados à baixa qualidade (GILLet.al., 1998; JAY, LOESSNER, GOLDEN, 2005). Enterobactérias e coliformes termotolerantes usualmente indicam contaminação de origem fecal.

De uma maneira geral, níveis de contaminação por aeróbios mesófilos abaixo de $10^{5} \mathrm{UFC} / \mathrm{cm}^{2}$ de carcaças bovinas indicam boas condições de higiene durante o abate. Contudo, em níveis acima de $10^{6} \mathrm{UFC} / \mathrm{cm}^{2}$ indicam início de processo de deterioração, com produção de odores típicos e redução do "shelflife" (tempo de prateleira). Quando o nível de contaminação atinge valores da ordem de $10^{7} \mathrm{UFC} / \mathrm{cm}^{2}$ a formação de limosidade já é evidente (GILL, 1998).

Durante o processo de abate dos bovinos, surgem diversas variáveis que contribuem no incremento à carga microbiana superficial sendo que, segundo Lambert, Smith e Dodds (1991), a esfola representa um ponto crítico do abate, devido às possibilidades de contaminação da superfície das carcaças a partir de micro-organismos da pele, pelos, material fecal e cascos dos animais. Adicionalmente, Gill et.al. (1998) afirmaram que a maior parte da contaminação das carcaças é originária da pele e pelos dos animais.

Outra etapa que merece destaque é a evisceração, pois durante a retirada do conjunto do trato gastrintestinal pode acorrer ruptura de vísceras com extravasamento de conteúdo gastrointestinal, sendo esta uma das importantes fontes de contaminação de carcaças segundo Schwach, (2007).

O modo mais eficiente de se reduzir a contaminação e o desenvolvimento microbiano em produtos cárneos é o estabelecimento de programas preventivos de controle de qualidade como Boas Práticas de Fabricação (BPF) e Hazard Analysis and Critical Control Points (HACCP), que podem ser validados e verificados pela pesquisa de microorganismos indicadores de higiene que além de remeterem às práticas adequadas de processamento, também sugerem a presença de patógenos e microorganismos causadores de deterioração (JAY, LOESSNER; GOLDEN, 2005).

Desta forma, o presente estudo buscou avaliar a contaminação de carcaças bovinas provenientes de um matadouro-frigorífico habilitado à exportação, localizado no oeste do Paraná, por meio da quantificação de aeróbios mesófilos (AM), enterobactérias (EB), coliformes a $35^{\circ} \mathrm{C}(\mathrm{CT})$ e $E$. coli (EC) para avaliação da eficiência higiênica do abate de bovinos segundo preconiza a decisão 471/2001 da União Europeia (até 3,5 Log UFC/ $/ \mathrm{cm}^{2}$ $\mathrm{AM}$ e até $\left.1,5 \mathrm{Log} \mathrm{UFC} / \mathrm{cm}^{2} \mathrm{~EB}\right)$.

\section{Materiais e Métodos}

Para a realização do presente trabalho foram colhidas amostras em um estabelecimento de abate de bovinos no Oeste do Paraná, com Serviço de Inspeção Federal (SIF) do Ministério da Agricultura, Pecuária e Abastecimento (Mapa) dotado de condições técnicas e higiênico-sanitárias adequadas (BPF e HACCP) e habilitado à exportação.

Entre o período de abril e julho de 2010 foi realizada colheita de amostras de superfície de 25 carcaças bovinas em quatro etapas do abate: A) na calha de sangria; B) após a esfola; C) após a evisceração; e D) após a lavagem final das meiascarcaças. Em cada etapa selecionada do abate (A, $\mathrm{B}, \mathrm{C}$ e D), as carcaças foram amostradas em quatro pontos superficiais distintos e aleatórios (Figura 1), com auxílio de esponjas abrasivas hidratadas com $10 \mathrm{~mL}$ de solução salina peptonada - SSP $0,2 \%$ (3M Dry Sponge) e moldes estéreis de $100 \mathrm{~cm}^{2}$ e de acordo com recomendações vigentes na Comunidade Europeia (EC, 2007), totalizando pool de $400 \mathrm{~cm}^{2}$. Cada sub-amostra foi obtida pela fricção de uma esponja. As esponjas foram acondicionadas em sacos plásticos estéreis e mantidas sob refrigeração até a realização das análises laboratoriais. 
Figura 1. Esquema representativo de meia carcaça bovina (lado externo direito e esquerdo com couro e lado externo e lado interno sem couro), com indicação dos pontos (*) onde ocorreu a coleta de amostras superficiais em áreas delimitadas de $100 \mathrm{~cm}^{2}(10 \mathrm{~cm} \times 10 \mathrm{~cm})$.
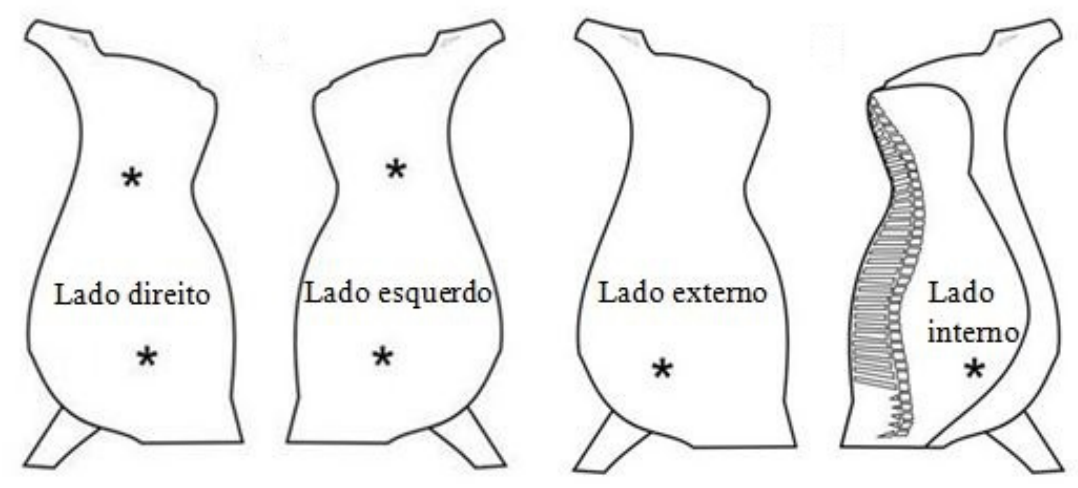

Fonte: Elaboração dos autores.

De acordo com a etapa de abate, as coletas seguiram o seguinte critério:

- Etapa A: após a realização da sangria as amostras foram obtidas em dois pontos de $100 \mathrm{~cm}^{2}$ na superfície externa esquerda e em dois pontos de $100 \mathrm{~cm}^{2}$ na superfície externa direita da carcaça com o couro, totalizando $400 \mathrm{~cm}^{2}$ em cada carcaça, e assim por diante nos mesmos pontos, seguinte à retirada do couro.

- Etapa de abate B (após a esfola): após a retirada do couro amostras foram obtidas em dois pontos de $100 \mathrm{~cm}^{2}$ na superfície externa esquerda e em dois pontos de $100 \mathrm{~cm}^{2}$ na superfície externa direita.

- Etapa C: após a realização da retirada das vísceras torácicas e abdominais e após a serragem das carcaças, as amostras foram obtidas a partir das duas meias-carcaças em quatro pontos de $100 \mathrm{~cm}^{2}$, dois na superfície externa e outros dois na superfície interna das duas meias-carcaças.

- Etapa D: após a lavagem final e antes de seguirem para a etapa de frigorificação, as amostras foram obtidas a partir das duas meias-carcaças e em quatro pontos de $100 \mathrm{~cm}^{2}$, dois na superfície externa e outros dois na superfície interna das duas meiascarcaças.

As coletas de amostras nas etapas selecionadas de abate foram realizadas com a mesma carcaça, que foi acompanhada durante todo o processo.

Em condições estéreis, cada conjunto de esponjas correspondente a cada uma das quatro etapas do abate (A, B, C e D), foi adicionado de $180 \mathrm{~mL}$ de SSP $0,2 \%$, homogeneizado em equipamento do tipo stomacher e em seguida, submetido às análises microbiológicas propostas.

Todos os homogeneizados obtidos foram submetidos a diluições seriadas decimais em e as contagens seguiram as recomendações do fabricante para cada tipo de Petrifilm ${ }^{\mathrm{TM}}$ utilizado. Os resultados foram expressos em $\mathrm{UFC} / \mathrm{cm}^{2} \mathrm{e}$ analisados estatisticamente pelo teste de variância (ANOVA) de uma via e teste de comparação de médias (Tuckey), utilizando nível de significância de 5\%. As análises foram realizadas utilizando o programa MSTAT-C, desenvolvido pela Michigan State University com múltiplas repetições.

\section{Resultados e Discussão}

Os resultados obtidos na contagem dos microorganismos indicadores (log de $\mathrm{UFC} / \mathrm{cm}^{2}$ ) estão distribuídos entre as Figuras 2 e 5. 
Os resultados obtidos nas análises de mesófilos aeróbios podem ser visualizados na figura 2 (entre 2,3 e $3,4 \log _{10} \mathrm{UFC} / \mathrm{cm}^{2}$ ). Estes resultados obtidos para as 25 carcaças analisadas nos 4 pontos distintos, nos 4 grupos de micro-organismos indicadores (AM, $\mathrm{EB}, \mathrm{CT}, \mathrm{EC}$ ) foram inferiores aos preconizados pela decisão 471/2001 da União Europeia, de até 3,5 Log UFC/cm² AM (EC, 2001). Foram inferiores, também, àqueles obtidos nas pesquisas de França Filho et.al. (2006) que relataram contagens entre 4,7e 4,5 $\log _{10}$ UFC/cm e aos níveis que Gill (1998) cita como indicadores de má higiene no abate de bovinos, ou seja, acima de $10^{5} \mathrm{UFC} / \mathrm{cm}^{2}$. Observase que houve redução da contaminação superficial por mesófilos principalmente ao se comparar as contagens obtidas entre os pontos de coleta A e D. Observa-se, também, que as carcaças 3,8,10,11,12,17 e 23 apresentaram aumento na contagem de AM em relação ao ponto $\mathrm{D}$, provavelmente devido a alguma contaminação cruzada das meias-carcaças durante a lavagem final das mesmas.

Figura 2. Contaminação obtida para a contagem de mesófilos aeróbios (AM) ao longo dos pontos de coleta (A, B, C e D) durante a linha de abate de bovinos $\left(\log \mathrm{UFC} / \mathrm{cm}^{2}\right)$.

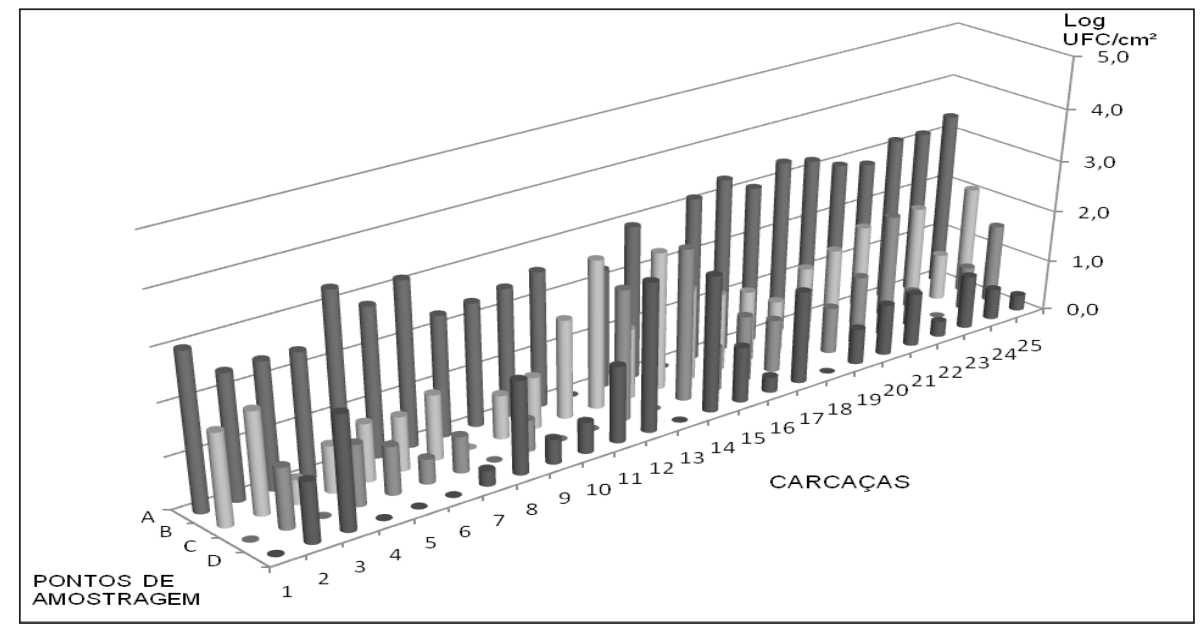

Fonte: Elaboração dos autores.

Os valores encontrados no presente estudo situam-se abaixo, ainda, dos valores encontrados por Hansson (2001) de até 4,92 $\log _{10} \mathrm{UFC} / \mathrm{cm}^{2}$ em abatedouros de alta capacidade e até $6,88 \log _{10}$ $\mathrm{UFC} / \mathrm{cm}^{2}$ em abatedouros de baixa capacidade (máximo de 20 animais/semana) para mesófilos aeróbios. Arenas et.al. (2004) encontraram valores semelhantes, entre 1,69 e 3,8 $\log _{10} \mathrm{UFC} / \mathrm{cm}^{2}$, na pesquisa realizada em um pequeno abatedouro na Venezuela, sendo as maiores contagens obtidas em swabs coletados próximo à região anal das carcaças.
As contagens médias de micro-organismos indicadores estão indicadas na Tabela 1, sendo possível observar que as maiores contagens obtidas para todos os grupos de micro-organismos pesquisados foram obtidas no ponto A. Em média, foi obtida uma contagem de $1,15 \log _{10} \mathrm{UFC} / \mathrm{cm}^{2}$ de enterobactérias no ponto A logo após a sangria. Com exceção do ponto C (após evisceração, Figura 3), em que a contagem média foi de 0,04 $\log _{10} \mathrm{UFC} / \mathrm{cm}^{2}$, em nenhum outro ponto foram observadas contagens, demonstrando estas serem 
abaixo do nível de detecção do método. As contagens para enterobactérias ficaram dentro dos padrões estabelecidos pela Decisão 471/2001 da União Europeia (EC, 2001), que considera aceitáveis níveis de até 1,5 $\mathrm{Log} \mathrm{UFC} / \mathrm{cm}^{2} \mathrm{em}$ amostras superficiais de carcaças bovinas. McEvoy et.al. (2003), encontraram números mais elevados, em torno de 2,75 $\log _{10} \mathrm{UFC} / \mathrm{cm}^{2}$ de contagem de enterobactérias antes da evisceração e 3,03 $\log _{10}$ $\mathrm{UFC} / \mathrm{cm}^{-2}$ após a lavagem das carcaças.

Tabela 1. Variação média dos micro-organismos indicadores $\left(\mathrm{UFC} / \mathrm{cm}^{2}\right)$ nos pontos amostrados ao longo da linha de abate.

\begin{tabular}{ccccccccc}
\hline \multicolumn{7}{c}{ MICRO-ORGANISMO INDICADOR (Log) } \\
\hline PONTOS & AM & DP & CT & DP & EB & DP & EC & DP \\
\hline A & $2,99^{\mathrm{b}}$ & 2,89 & $1,53^{\mathrm{b}}$ & 1,92 & $1,82^{\mathrm{b}}$ & 2,14 & $-1,27^{\mathrm{b}}$ & 1,51 \\
B & $1,92^{\mathrm{a}}$ & 2,21 & $-0,38^{\mathrm{a}}$ & 0,30 & $-0,62^{\mathrm{a}}$ & $-0,12$ & $-1,70^{\mathrm{a}}$ & $-0,70$ \\
C & $1,81^{\mathrm{a}}$ & 2,26 & $-1,70^{\mathrm{a}}$ & $-1,00$ & $-0,11^{\mathrm{a}}$ & 0,44 & $-1,40^{\mathrm{a}}$ & 0,00 \\
D & $1,80^{\mathrm{a}}$ & 2,22 & $0,00^{\mathrm{a}}$ & 0,00 & $-1,70^{\mathrm{a}}$ & $-1,00$ & $0,00^{\mathrm{a}}$ & 0,00 \\
MÉDIA & 1,46 & & 0,30 & & 0,23 & & 0,21 & \\
\hline
\end{tabular}

(*) Médias seguidas pela mesma letra (nas colunas) não diferem pelo teste de Tuckey ao nível de 5\% de significância (Colunas AM, CT, EB e EC).

AM. Mesófilos aeróbios.

EB. Enterobactérias.

CT. Coliformes a $35^{\circ} \mathrm{C}$.

EC. Escherichia coli.

DP. Desvio padrão.

Fonte: Elaboração dos autores.

Figura 3. Contaminação obtida para a contagem de enterobactérias (EB) ao longo dos pontos de coleta (A, B, C e D) durante a linha de abate de bovinos $\left(\log \mathrm{UFC} / \mathrm{cm}^{2}\right)$.

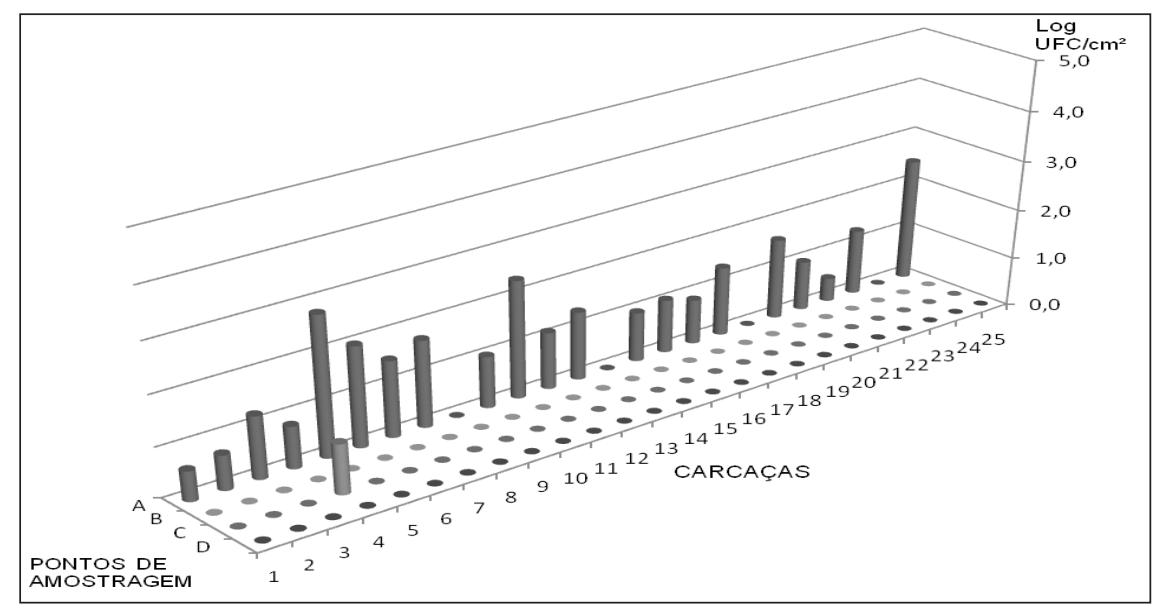

Fonte: Elaboração dos autores.

Pela figura 4, observa-se que para o grupo dos coliformes a $35^{\circ} \mathrm{C}$, foram obtidas contagens baixas. As coletas na etapa A apresentaram de 0 à 2,6 $\log _{10}$ $\mathrm{UFC} / \mathrm{cm}^{2}$ (em média 0,99 $\log _{10} \mathrm{UFC} / \mathrm{cm}^{2}$ ) sendo reduzidas à zero (não detectável) já na segunda etapa, onde a esfola já tinha sido iniciada (Etapa B). Apenas a carcaça número 5 amostrada apresentou contaminação por CT na Etapa B de amostragem, 1 $\log _{10} \mathrm{UFC} / \mathrm{cm}^{2}$. 
Figura 4. Contaminação obtida para a contagem de coliformes a $35^{\circ} \mathrm{C}(\mathrm{CT})$ ao longo dos pontos de coleta $(\mathrm{A}, \mathrm{B}, \mathrm{C}$ e D) durante a linha de abate de bovinos $\left(\log \mathrm{UFC} / \mathrm{cm}^{2}\right)$.

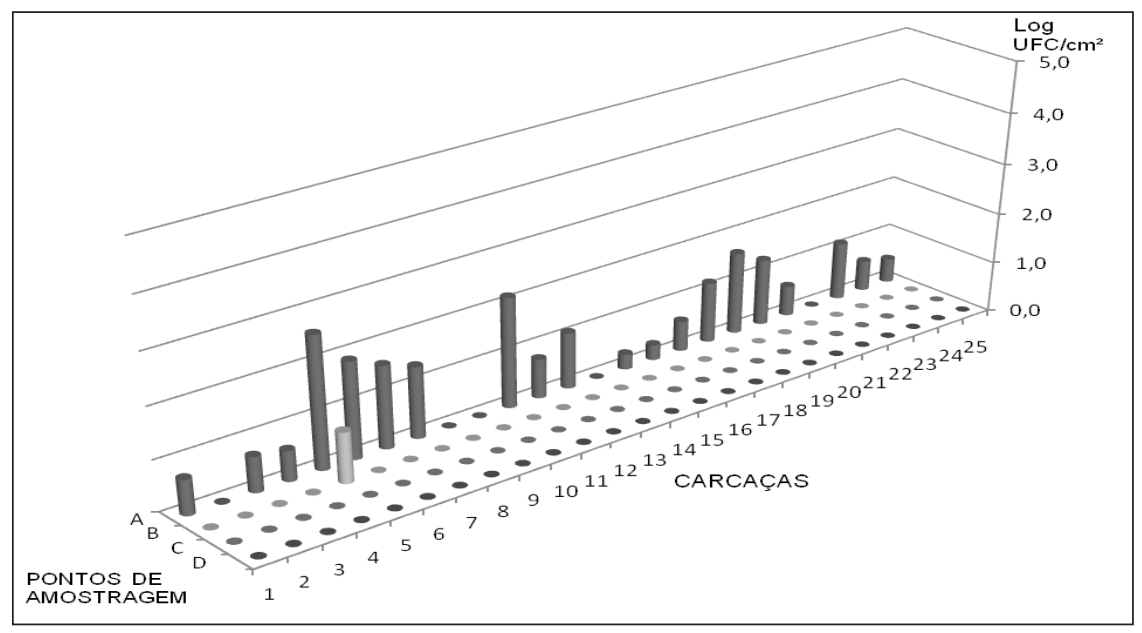

Fonte: Elaboração dos autores.

A contagem máxima obtida para $\mathrm{CT}$, de 2,2 $\log _{10} \mathrm{UFC} / \mathrm{cm}^{2}$ é bem superior aos $0,65 \log _{10} \mathrm{UFC} /$ $\mathrm{cm}^{2}$ obtidos por Jardim et. al. (2006) que obtiveram contagem de 1,27 para animais a pasto e $0,64 \log _{10}$ $\mathrm{UFC} / \mathrm{cm}^{2}$ nos animais em confinamento. Estes autores, entretanto, observaram uma manutenção da contaminação após a esfola e após a lavagem das carcaças, de 0,4 $\log _{10} \mathrm{UFC} / \mathrm{cm}^{2}$ de CT e EC, tanto para os animais de confinamento quanto para aqueles a pasto. Neste estudo, após a esfola, apenas uma amostragem apresentou manutenção da contaminação $\left(1 \log _{10} \mathrm{UFC} / \mathrm{cm}^{2}\right.$ de CT e $0,7 \log _{10}$ $\mathrm{UFC} / \mathrm{cm}^{2}$ de $E$. coli, segundo apresentado na Figura 5 , ambos sendo reduzidos a zero após a lavagem das carcaças.

Os demais pontos de amostragem, subsequentes à retirada do couro (ponto $\mathrm{A}$ ), não apresentaram contaminação pelos indicadores pesquisados. As contagens de E. coli no ponto "A", segundo a Figura 5, variaram entre 0 e 2,2 $\log _{10} \mathrm{UFC} / \mathrm{cm}^{2}$, sendo reduzidas a zero no último ponto amostrado, após a lavagem final das carcaças. Schwach (2007) descreve a avaliação da contaminação por $E$. coli em dois pontos distintos, um antes e um depois da implantação de um ponto crítico de controle - PCC para contaminação gastrointestinal de carcaças bovinas antes da lavagem final das mesmas. $\mathrm{O}$ autor encontrou valores em torno de $1,02 \log _{10}$ para o grupo de carcaças analisadas antes da implantação do PCC e 0,26 $\log _{10}$ para o grupo posterior à implantação.

Os resultados das contagens em Petrifilm ${ }^{\mathrm{TM}}$ para mesófilos aeróbios na Etapa A foram significativamente diferentes do número de enterobactérias, coliformes a $35^{\circ} \mathrm{C}$ e $E$. coli (pela média observou-se que foi estatisticamente maior). Não houve diferença entre o número de enterobactérias, coliformes a $35^{\circ} \mathrm{C}$ e E.coli.

Realizando-se o teste de ANOVA com repetições múltiplas para evidenciação da variação da carga contaminante ao longo das etapas A, B, C e D de abate, pôde ser verificada uma diferença estatística significativa no ponto A (tabela 1) para cada um dos indicadores pesquisados (mesófilos aeróbios, enterobactérias, coliformes a $35^{\circ} \mathrm{C}$ e E.coli). 
Figura 5. Contaminação obtida para a contagem de $E$. coli (ec) ao longo dos pontos de coleta (A, B, C e D) durante a linha de abate de bovinos (Log UFC/ $\left.\mathrm{cm}^{2}\right)$.

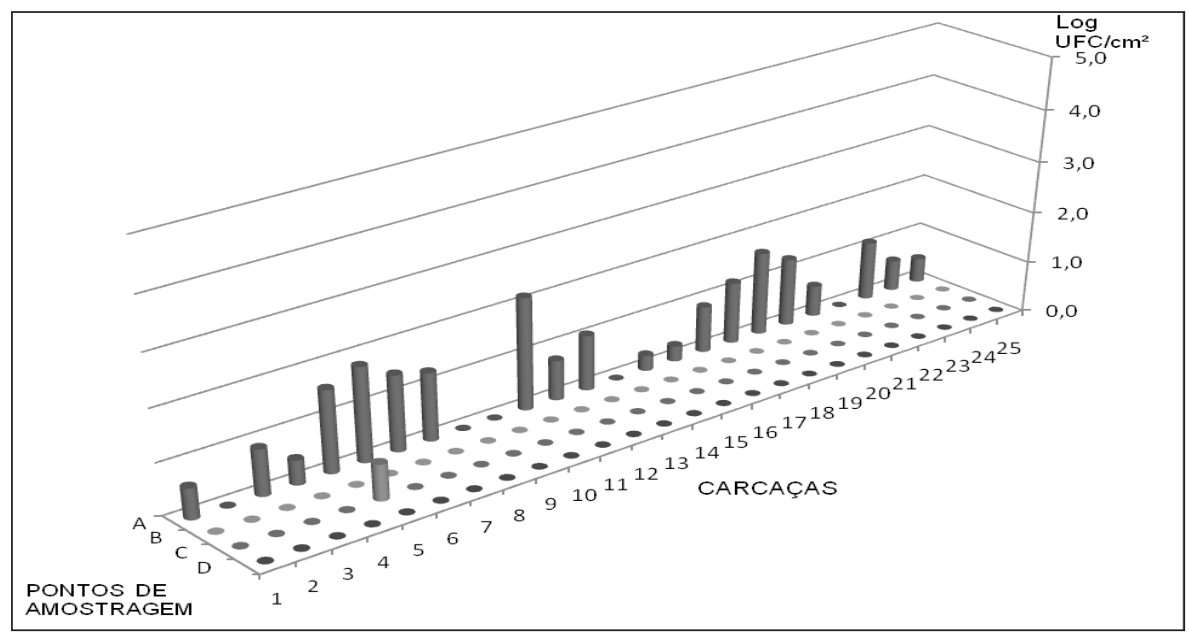

Fonte: Elaboração dos autores.

\section{Conclusões}

A partir dos resultados obtidos nessa pesquisa foi possível concluir que o processo tecnológico de abate na indústria avaliada, durante o período e nas condições amostradas, foi satisfatório para a garantia de manutenção da inocuidade das carcaças.

A enumeração de micro-organismos indicadores ao longo do processo de abate como forma de monitoramento da contaminação mostrou-se eficiente, assim como a utilização de grupos de indicadores mais específicos como os coliformes, enterobactérias e/ou E. coli, por fornecerem informações mais concretas sobre a ocorrência de contaminações por fezes, contaminações cruzadas e presença de enteropatógenos, entre outros.

As baixas contagens de micro-organismos indicadores, chegando a níveis não detectáveis pelos métodos utilizados, no último ponto de amostragem, após a lavagem final das carcaças, reforçam a eficiência dos programas de controle e garantia de qualidade da indústria no fornecimento de alimentos inócuos ao consumidor.

\section{Agradecimentos}

Ao Conselho Nacional de Desenvolvimento Científico e Tecnológico (CNPq) pelo financiamento desta pesquisa e pelas bolsas de produtividade em pesquisa de LA Nero e PSA Pinto.

\section{Referências}

ARENAS, M. L.; HUERTA-LEIDENZ, N.; ORTIZ, Y.; VALERA-MATOS, M.; SMITH, C. G. Microbiological contamination on beef carcasses in a small abattoir in Venezuela. Departmental Research Reports Colorado State University, 2004. Disponível em: <http://ansci. colostate.edu/content/view/51/>. Acesso em: 10 jun. 2010.

\section{COMMISSION REGULATION - EUROPEAN} COMMUNITY - EC. n. 1441/2007, amending regulation (EC) n. 2073/2005 on microbiological criteria for foodstuffs. Official Journal of the European Union, 18, p. 5, dez. 2007. Disponível em: <http://eur-lex. europa.eu/LexUriServ/LexUriServ.do?uri=OJ:L:2007: 322:0012:0029:EN:PDF>. Acesso em: 23 jun. 2010.

. n. 471/2001. Official Journal of the European Union. Luxemburgo: Publicações da União Europeia, L.165, p. 48-53, 8 Junho 2001. 
FRANÇA FILHO, A. T.; MESQUITA, A. J.; OLIVEIRA, J. P.; BUENO, C. P.; LOPES, J. H.; COUTO, M. V.; BORGES, N. M. F. Qualidade bacteriológica de meiascarcaças bovinas oriundas de matadouros-frigoríficos do estado de Goiás habilitados para exportação. Ciência Animal Brasileira, Goiânia, v. 7, n. 3, p. 315-325, jul./ set. 2006. Disponível em: <http://www.revistas.ufg.br/ index.php/vet/article/viewFile/406/381>. Acesso em: 12 ago. 2010 .

GILL, C. O. Microbiological contamination of meat during slaughter and butchering of cattle, sheep and pigs. In: DAVIES, A.; BOARD, R. (Ed.). The microbiology of meat and poultry. London: Blackie Academic and Professional, 1998. p. 118-157.

GILL, C. O.; DESLANDES, B.; RAHN, K.; HOUDE, A.; BRYANT, J. Evaluation of the hygienic performances of the processes for beef carcass dressing at 10 packing plants. Journal of Applied Microbiology, Bedford, v. 84, n. 6, p. 1050-1058, 1998. Disponível em: <http://onlinelibrary.wiley.com/doi/ 10.1046/j.13652672.1998.00441.x/pdf>. Acesso em: 01 out. 2010.

HANSSON, I. B. Microbiological meat quality in highand low-capacity slaughterhouses in Sweden. Journal of Food Protection, Ames, v. 64, n. 6, p. 820-825, 2001. Disponível em: <http://www. ingentaconnect.com/ content/iafp/jfp/2001/00000064/00000006/art00011>. Acesso em: 5 out. 2010.
JARDIM, F. B. B.; SILVA, E. N.; OKURA, M. H.; RAMOS, M. A. Influência dos sistemas de pastagem e confinamento na contaminação microbiana de carcaças bovinas. Ciênc. Tecnol. Aliment., v. 26, n. 2, p. 277282, 2006. Disponível em: <www.scielo.br/pdf/cta/ v26n2/30173.pdf>. Acesso em: 28 jul. 2010.

JAY, J. M.; LOESSNER, M. J.; GOLDEN, D. A. Modern food microbiology. 7. ed. New York: Springer, 2005, 790 p.

LAMBERT, A. D.; SMITH, J. P.; DODDS, K. L. Shelf life extension and microbiological safety of fresh meat. A review. Food Microbiology, v. 8, n. 4, p. 267-97, 1991. Disponível em: $<$ http://www.sciencedirect. com/science/ article/B6WFP-4H9PHTJ-2/2/3aa420c9397e08abe04bb 7d65646e382>. Acesso em: 27 jul. 2010.

MCEVOY, J. M.; DOHERTY, A. M.; SHERIDAN, J. J.; BLAIR, I. S.; MCDOWELL, D. A. The prevalence of Salmonella spp. in bovine faecal, rumen and carcass samples at a commercial abattoir. Journal of Applied Microbiology, n. 94, p. 69-700, 2003. Disponível em: $\quad<$ http://sullivanfiles.net/324/visitors/mcevoy/ Manuscript1.pdf $>$. Acesso em: 19 jun. 2010.

SCHWACH, E. Validação do sistema de monitoramento para redução da contaminação microbiana em carcaças bovinas. 2007. Dissertação (Mestrado em Medicina Veterinária) - Universidade Estadual Paulista Júlio de Mesquita Filho, Botucatu. 